\title{
Mercosul educativo na carreira de Enfermagem
}

\author{
Educational Mercosur in the Nursing career \\ Mercosur educativo en la carrera de Enfermeria
}

\section{Roseli Schmoeller', Mariana Cabral Schveitzer", Cecilia Arruda'II, Vânia Marli Schubert Backes' ${ }^{\text {IV }}$ Marta Lenise do Pradov", Jussara Gue Martini" ${ }^{v 1}$}

\begin{abstract}
'Universidade Federal de Santa Catarina, Departamento de Enfermagem, Núcleo de Estudos sobre Trabalho, Cidadania, Saúde e Enfermagem (Membro). Florianópolis-SC, Brasil.

"Universidade de São Paulo, Escola de Enfermagem, Programa de Pós-Graduação em Enfermagem (Doutoranda) São Paulo-SP, Brasil.

II' Universidade Federal de Santa Catarina, Programa de Pós Graduação em Enfermagem (Doutoranda), Núcleo de Estudos e Assistência em Enfermagem e Saúde a Pessoas com Doenças Crônicas (Membro). Florianópolis-SC, Brasil.

IV Universidade Federal de Santa Catarina, Programa de Pós Graduação em Enfermagem, Grupo de Pesquisas em Educação em Enfermagem e Saúde (Líder). Pesquisadora do CNPq. Florianópolis-SC, Brasil.

${ }^{v}$ Universidade Federal de Santa Catarina, Programa de Pós Graduação em Enfermagem. Vice-líder do Grupo de Pesquisa em Educação em Enfermagem. Pesquisadora do CNPq. Florianópolis-SC, Brasil.

${ }^{V}$ Universidade Federal de Santa Catarina, Departamento de Enfermagem, Programa de Pós Graduação em Enfermagem, Grupo de Pesquisa em Educação em Enfermagem (Membro). Florianópolis-SC, Brasil.
\end{abstract}

Submissão: 07-02-2011 Aprovação: 05-09-2012

\section{RESUMO}

O Mercosul, instituído com vistas à integração econômica, política, social e cultural entre os países membros, atualmente destaca-se pelas estratégias integrativas de âmbito educacional. Este artigo aborda os movimentos acerca da formação acadêmica dos cursos de Enfermagem e o trajeto histórico de integração educacional, apresentando o Sistema de Acreditação dos Cursos Universitários do Mercosul, o ARCU-SUL, além dos setores responsáveis por esse processo e as perspectivas para a Enfermagem nos países do Mercosul. Entendemos que para o desenvolvimento de profissionais críticos, reflexivos e com compromisso político-social, é fundamental investir na formação e na qualidade dos centros de ensino em Enfermagem.

Descritores: Enfermagem; Educação; Acreditação.

\begin{abstract}
The Mercosul, established with the objective of integrate economics, political, social and cultural differences among member countries, currently is highlighted by its strategies of educational framework. This article discusses the movement on the academic background of the Nursing career and the history of educational integration, presenting the accreditation system for university courses of Mercosul, the Arcu-Sul, and also the sectors responsible for this process and the prospects for Nursing in Mercosul. We believe that for the development of a critic, reflective and social-political committed professional is essential to invest in training and in the quality of education centers in Nursing.
\end{abstract}

Key words: Nursing; Education; Accreditation.

\section{RESUMEN}

El Mercosur, establecido con miras a la integración económica, el intercambio político, social y cultural entre los países miembros, actualmente se destaca por las estrategias del marco educativo. Este artículo aborda el movimiento en la formación académica de la carrera de Enfermería y el récord del campo de la integración educativa, al presentar el sistema de acreditación de carreras universitarias del Mercosur, el Arcu-Sur, y los sectores responsables de este proceso y las perspectivas para la Enfermería en el Mercosur. Creemos que para el desarrollo de profesionales críticos, reflexivos y con el compromiso socialpolítico es esencial invertir en la formación y en la calidad de los centros de educación en enfermería.

Palabras clave: Enfermería; Educación; Acreditación. 


\section{INTRODUÇÃO}

A necessidade de integração econômica, política, social e cultural entre os países torna-se cada vez mais imprescindível, na medida em que a competição ligada a novos arranjos na divisão internacional do trabalho demanda trabalhadores mais especializados e, entre as tentativas de integração, destacamse as de âmbito educacional no Mercosul ${ }^{(1-3)}$.

Este estudo pretende descrever os movimentos atuais acerca da formação acadêmica para os cursos de Enfermagem e do seu trajeto histórico de integração educacional, apresentando os setores responsáveis por esse processo e as perspectivas para os países participantes do Mercosul.

\section{MERCOSUL EDUCATIVO}

O Mercosul foi instituído em 26 de março de 1991, pelo Tratado de Assunção, como um projeto de integração envolvendo dimensões econômicas, políticas e sociais, a serem tratadas por diversos órgãos e instâncias com representação dos Estados Partes, caracterizado pelo regionalismo aberto. A criação do bloco teve por objetivo o incremento do comércio intrazona, como também o estímulo às trocas com terceiros países ${ }^{(4-6)}$.

Nesse período, os Estados Partes formados por Argentina, Brasil, Paraguai e Uruguai acordaram em ampliar as dimensões dos seus mercados nacionais, com base na premissa de que a integração constitui condição fundamental para acelerar o processo de desenvolvimento econômico e social de seus povos. Estabeleceram, no preâmbulo do Tratado de Assunção, que a constituição do mercado comum deveria pautar-se pelo aproveitamento mais eficaz dos recursos disponíveis, pela preservação do meio ambiente, pela melhora das interconexões físicas e pela coordenação de políticas macroeconômicas de complementação dos diferentes setores da economia ${ }^{(4-5,7)}$.

$\mathrm{Na}$ sua configuração, além dos Estados Partes, são Estados Associados do Mercosul a Bolívia (desde 1996), o Chile (desde 1996), o Peru (desde 2003), a Colômbia e o Equador (desde 2004). O Tratado de Assunção é aberto, mediante negociação, à adesão dos demais Países Membros da ALADI (Associação Latino-Americana de Integração). Nesse sentido, foi assinado, em 04 de julho de 2006, o Protocolo de Adesão da República Bolivariana da Venezuela ao Mercosul ${ }^{(1,4-5,7)}$.

Com base no Protocolo de Ouro Preto firmado em 17 de dezembro de 1994, e vigente desde 15 de dezembro de 1995 o MERCOSUL tem uma estrutura institucional básica composta pelo: 1) Conselho do Mercado Comum (CMC), órgão supremo cuja função é a condução política do processo de integração, formado pelos Ministros de Relações Exteriores e de Economia dos Estados Partes, que se pronunciam através de decisões; 2) Grupo Mercado Comum (GMC), órgão decisório executivo, responsável de fixar os programas de trabalho e de negociar acordos com terceiros em nome do Mercosul, se pronuncia por resoluções e está integrado por representantes dos Ministérios de Relações Exteriores e de Economia, e dos Bancos Centrais dos Estados Parte; 3) Comissão de Comércio do Mercosul (CCM), um órgão decisório técnico, é o responsável por apoiar o GMC no que diz respeito à política comercial do bloco ${ }^{(1,4-8)}$

Ainda com referência ao protocolo acima citado, são definidos os Órgãos Consultivos do Mercosul: 4) Comissão Parlamentar Conjunta (CPC), órgão de representação parlamentar, integrada por até 64 parlamentares, 16 de cada Estado Parte; 5) Foro Consultivo Econômico Social (FCES), é um órgão consultivo que representa os setores da economia e da sociedade, que se manifesta por Recomendações ao GMC; 6) Comissão de Representantes Permanentes do Mercosul (CRPM), que é um órgão permanente do CMC, cuja função principal é apresentar iniciativas ao CMC sobre temas relativos ao processo de integração, as negociações externas e a conformação do Mercado Comum ${ }^{(1,4-8)}$

A estrutura do Mercosul também comporta órgãos específicos de Solução de Controvérsias, como os Tribunais ad-hoc e o Tribunal Permanente de Revisão. O Mercosul funciona habitualmente mediante Reuniões de Ministros (RM), Reuniões Especializadas (RE), conferências, e Reuniões ad-hoc. Ademais, a Secretaria do Mercosul fornece apoio técnico a Estrutura Institucional do Mercosul ${ }^{(1,4-8)}$.

A livre movimentação de pessoas entre países fomenta a integração, disseminação e intercâmbio de cultura e do conhecimento. E no setor educacional, esta integração e mobilidade é um mecanismo que poderá facilitar a integração nos países do Mercosul.

Dessa forma, com o objetivo de valorizar a formação dos profissionais de saúde, especialmente na área de enfermagem, de forma a viabilizar e oferecer formação acadêmica com qualidade e com o reconhecimento internacional, foi criado o Setor Educativo do Mercosul a partir da assinatura do Protocolo de Intenções pelos Ministros da Educação ${ }^{(1)}$.

Desde sua criação reconheceu-se a importância da educação como estratégia para o desenvolvimento da integração econômica e cultural do Mercosul e o peso da informação para se alcançarem esses objetivos, o que culminou com a criação do Comitê Coordenador Técnico do Sistema de Informação e Comunicação (SIC) a partir da Reunião de Ministros da Educação (RME) em dezembro de 1991 (1-3,5,7-8).

Nesse sentido, foram definidas algumas linhas de ação do SIC, a saber: Criação e atualização dos espaços virtuais para publicar os materiais e produtos surgidos nos diferentes encontros e seminários; Elaboração de indicadores de Educação Tecnológica pertinentes e, incorporação à publicação do sistema de Indicadores do Mercosul Educacional; Publicação dos Indicadores de Educação Básica, Média e Educação Superior; Elaboração de um Glossário relativo à Educação Técnica e a Educação Tecnológica; Difusão dos programas de intercâmbio existentes e as equivalências e protocolos acordados; Difusão das ações do SEM nos sistemas educacionais nacionais, nas jurisdições responsáveis pela gestão escolar, nas comunidades educacionais e no conjunto da sociedade; Favorecimento da circulação do conhecimento: manter atualizada a informação promovida pelo órgão e usar os espaços de comunicação e difusão para o setor educacional; Fortalecimento dos laços nacionais do SIC; e Criação de políticas de informação, comunicação e gestão do conhecimento, no âmbito educacional regional ${ }^{(1,8)}$. 
Nesse processo integrador, o Setor Educativo do Mercosul tem desenvolvido planejamentos para os diferentes níveis educativos. Estes planejamentos têm definido a missão, os objetivos e os princípios que orientam as atividades. A missão do SEM no Plano Operacional 2006-2010: "formar um espaço comum de ensino, através da coordenação das políticas de educação, que combinam com a forma e com o processo de integração do Mercosul; o incentivo à mobilidade, o intercâmbio e a formação de uma identidade e cidadania regional a fim de alcançar uma educação de qualidade para todos, com especial atenção aos mais vulneráveis no processo de desenvolvimento com justiça social e respeito à diversidade cultural dos povos de uma região"(1:6).

Dentre os objetivos do Plano Operacional vigente do SEM, período 2006-2010, destacam-se: Contribuir para a integração regional agenciando e executando políticas educativas para promover a cidadania regional, uma cultura de paz e de respeito para a democracia e para os direitos humanos e do meio ambiente; Promover educação de qualidade para todos como fator de inclusão social para o desenvolvimento humano e produtivo; Promover a cooperação solidária e o intercâmbio para melhorar os sistemas educativos; Fomentar e fortalecer os programas de mobilidade de estudantes, estagiários, docentes, pesquisadores, gestores e profissionais; Promover políticas que articulem a educação com a integração do Mercosul. Os princípios e as características orientadoras das ações do Plano Operativo do SEM 2006-2010 são: a Confiança, o Respeito e o Consenso, a Solidariedade, a Cooperação, a Difusão e a Visibilidade, a Gradualidade, o Diálogo e a Interação ${ }^{(8)}$

A partir destes princípios e objetivos este trabalho pretende elucidar a evolução histórica do Sistema de Acreditação no Mercosul, destacando o ensino superior na carreira de enfermagem, visto como ferramenta fundamental para promoção da saúde e da cidadania em cada país participante.

\section{O SISTEMA DE ACREDITAÇÃO NO MERCOSUL}

Serão apresentadas a seguir a origem e a construção do Sistema de Acreditação dos cursos universitários do Mercosul, sua base orientadora, finalidade e princípios, grupos e instituições responsáveis pela administração e implementação das atividades, além do caminho a ser percorrido pelas instituições educacionais de nível superior que desejam passar pelo processo de acreditação.

O sistema de Acreditação Regional de Cursos Universitários para o Mercosul - ARCU-SUL - foi criado a partir de um processo prévio denominado Mecanismo Experimental de Acreditação (MEXA), aplicado em um número limitado de cursos: Agronomia, Engenharia e Medicina. Estes três cursos foram designados pela Reunião de Ministros da Educação para dar início ao processo experimental ${ }^{(1,4)}$.

Os países participantes deste processo experimental foram: Argentina, Brasil, Paraguai, Uruguai, Bolívia e Chile. Nesse período foram acreditados 19 cursos de Agronomia, 29 de Engenharia e 14 de Medicina. Desta forma, comprovou-se que o processo de Acreditação realizado pelo Setor Educativo do
Mercosul (SEM) era adequado e apresentava-se conveniente a instalação de um sistema de acreditação permanente para verificar a qualidade da formação em nível universitário nos países do Mercosul experimental ${ }^{(1,4)}$

O delineamento do MEXA foi iniciado em 1998, sendo o processo de avaliação dos cursos compreendido entre os anos de 2004 a 2006. A Reunião de Ministros da Educação, celebrada em 24 de novembro de 2006, em Belo Horizonte/ Brasil, deu por concluída a etapa do MEXA e aprovou um plano de trabalho para a elaboração do sistema de acreditação permanente - o ARCU-SUL, sob a responsabilidade das Agências Nacionais de Acreditação (ANA) $)^{(1,4)}$.

As bases orientadoras para a constituição do sistema ARCU-SUL foram definidas em um memorando aprovado pela Reunião de Ministros da Educação, realizada em 09 de novembro de 2007, em Montevideo/Uruguai. Posteriormente, este memorando assumiu caráter de Acordo através de uma decisão do Grupo Mercado Comum. A decisão n ${ }^{\circ}$ 17/08 assinada em São Miguel de Tucumán/Argentina, em 30 de junho de 2008, aprova o texto que fixa as bases definitivas do Sistema ARCU-SUL, através do documento "Acordo sobre a Acreditação e Implementação de um Sistema de Acreditação de Cursos Universitários para o reconhecimento Regional da Qualidade Acadêmica de suas respectivas Titulações no Mercosul e Estados Associados"(1).

Este sistema apresenta como finalidade a melhora permanente da formação das pessoas, com padrões de qualidade requeridos para a promoção do desenvolvimento econômico, social, político e cultural dos povos integrantes do Mercosul. Assim, se desenvolve no sentido da consolidação de uma sociedade de conhecimento e uma comunidade científica regional, orientadas para a constituição de um mundo igualitário e de paz, onde prevaleça a responsabilidade, a defesa dos direitos humanos, o meio ambiente e a cooperação solidária. A implementação do Sistema ARCU-SUL baseia-se em um Planejamento que contém ações e metas definidas até o ano 2010, em sintonia com o Plano operacional 2006-2010 definido no Setor Educativo do Mercosul (SEM), já citado perviamente neste estudo ${ }^{(1)}$.

Eis alguns princípios gerais do Sistema ARCU-SUL: A Acreditação é resultado do processo de avaliação, mediante o qual se certifica a qualidade acadêmica; O Sistema respeita tanto a legislação de cada país como a autonomia das instituições universitárias; A adesão ao Sistema é de caráter voluntário; O processo de Acreditação compreende uma auto-avaliação por parte do curso, uma avaliação externa por comitês de pares e uma resolução de Acreditação, de responsabilidade da Agência Nacional da Acreditação (ANA); e a Acreditação tem vigência por um prazo de seis anos, sendo reconhecida por todos os Estados Membros e Associados do Mercosul que aderiram ao Acordo $^{(1)}$.

A administração do Sistema ARCU-SUL é de responsabilidade das Agências Nacionais de Acreditação (ANA), que são entidades específicas que desenvolvem os processos de avaliação e acreditação da educação superior designadas pelos Estados Parte ou Associados do Mercosul. Alguns atributos devem ser observados para designação das ANA's: devem ser 
instituições públicas, reconhecidas por disposições legais e constitucionais do país de origem; devem ser dirigidas por um órgão colegiado; devem dar garantia de autonomia e imparcialidade, estarem integradas por membros e pessoas idôneas e utilizarem procedimentos adequados às boas práticas internacionais ${ }^{1}$ No Brasil, a instituição que preenche tais requisitos é a Comissão Nacional de Avaliação de Educação Superior - CONAES, e, portanto nossa representante como ANA.

As Agências Nacionais de Acreditação estão organizadas em rede, chamada Rede de Agências Nacionais de Acreditação - RANA, e tem por finalidade: a execução do Plano Operativo 2006-2010; cumprimento dos acordos e assumo das decisões e procedimentos estabelecidos pelo MCM (Conselho do Mercado Comum) e RME (Reunião de Ministros da Educação), no que concerne a implementação do Sistema ARCU-SUL. São membros plenos da RANA as Agências Nacionais de Avaliação e Acreditação Universitária. A coordenação das atividades é assumida pela Agência do país sede da Secretaria pró-tempore do Mercosul Educativo, a qual muda semestralmente entre os países membro. A RANA se reúne de forma ordinária pelo menos quatro vezes ao ano ${ }^{(1)}$.

Assim, a RANA é responsável pela elaboração da carta-convite para a Acreditação pelo Sistema ARCU-SUL e cada Agência Nacional deve realizar a divulgação do edital de convocação ao processo de Acreditação, informando as instituições de educação superior sobre os requisitos que devem cumprir para incorporarem-se ao processo.

Em julho de 2009, a Secretaria de Educação Superior SESu do Ministério da Educação, membro da Comissão Regional Coordenadora da Educação Superior - CRC-ES e representante do Brasil no Setor Educacional do Mercosul - SEM, em conjunto com a Comissão Nacional de Avaliação da Educação Superior - CONAES, membro da Rede de Agências Nacionais de Acreditação - RANA, considerando a Decisão No 17/08 do Conselho Mercado Comum (CMC), que aprova o Sistema de Acreditação de Cursos Universitários - ARCU-SUL, encaminhado ao CMC pela Reunião de Ministros da Educação (RME) do Setor Educacional do Mercosul - SEM e a Portaria do Ministério da Educação No 1004 de 13 de agosto de 2008, publicaram o CONVITE para as candidaturas de cursos de caráter universitário para o primeiro ciclo de acreditação de cursos de graduação nas áreas de Enfermagem e Veterinária conforme os procedimentos e critérios aprovados pela Rede de Agências Nacionais de Acreditação - RANA.

Segundo este edital, para a participação no processo as instituições devem cumprir as seguintes condições: ter caráter universitário, ou seja, desenvolver atividades de ensino, pesquisa e extensão; ter pelo menos dez anos de funcionamento; participar de processos avaliativos do Sistema Nacional de Avaliação da Educação Superior - SINAES, tendo obtido conceito igual ou maior a 4,0 (quatro); e por meio do coordenador de curso e com aprovação do pró-reitor de graduação ou cargo equivalente, elas devem firmar termo de compromisso de participação voluntária. Neste primeiro ciclo serão acreditados até vinte cursos brasileiros de Enfermagem pelo sistema ARCU-SUL.

$O$ processo de Acreditação ocorre em torno de um ano de duração. Para isso são previstos em média 60 dias entre a divulgação da Carta-Convite e a solicitação da Acreditação por escrito por parte das Instituições de Educação Superior (IES) às Agências Nacionais de Acreditação (ANAs) correspondentes. Esta solicitação deve conter a identificação da IES solicitante, os cursos com interesse na avaliação, a declaração explícita de que cumpre os requisitos básicos para passar pelo processo de Acreditação, que aceita os critérios e normas do sistema ARCU-SUL. Além de manter-se com o compromisso de apresentar o informe de autoavaliação e, posteriormente, o recebimento da visita do Comitê de Pares Avaliadores. A aprovação desta solicitação é dada dentro de 30 dias.

Os próximos seis meses serão destinados ao preparo dos documentos por parte das IES e entrega do informe de autoavaliação às respectivas ANAs. A constituição de Comitês de Pares deve ocorrer dentro de 30 dias, ou seja, devem ser formados grupos com três ou mais profissionais capacitados que são designados por cada ANA como avaliadores em suas áreas de conhecimento. Este Comitê de Pares deve ser formado por pelo menos dois representantes dos Estados Partes ou Associados do Mercosul, diferentes do país organizador da Acreditação. Os Comitês de Pares Avaliadores devem analisar o informe de autoavaliação, rever as informações emitidas pelas IES e preparar suas visitas locais, também dentro de 30 dias.

As visitas externas têm a duração de três a cinco dias, e então, os Pares Avaliadores têm o prazo de 30 dias para entregarem seus relatórios às ANAs. Estes relatórios são encaminhados às IES, que, dentro de 15 dias, analisam as informações geradas pelos visitadores e retornam suas observações às ANAs. Em seguida, as ANAs enviam novamente as informações aos Comitês de Pares. Assim, finalmente, é elaborado o relatório final pelos Comitês de Pares para as ANAs, que são responsáveis por, dentro de 30 dias, emitir um parecer a ser explanado na Reunião das Agências e dos Ministros da Educação e então entregar às IES o parecer final com os resultados da avaliação, tornando a IES solicitante acreditada ou não.

Portanto, trata-se de um processo complexo, que demanda um grande quadro de pessoal idôneo, comprometido e organizado além de alguma burocracia e tempo. Apesar de ser um processo recente, pois se desenvolveu há pouco mais de 10 anos, o Sistema ARCU-SUL mostra avanços importantes como um modelo avaliativo adequado que busca garantir a qualidade do ensino superior nos Estados Partes e Associados do Mercosul e promover seu reconhecimento mútuo.

\section{PERSPECTIVAS DO SETOR EDUCACIONAL DE ENFERMAGEM NO MERCOSUL}

No mundo moderno, as práticas de saúde analisam as ações de cuidado e, em especial, as de Enfermagem, sob a ótica do sistema político-econômico da sociedade, ressaltando o surgimento da Enfermagem como atividade profissional institucionalizada. No início deste processo, destaca-se como marco da Enfermagem mundial, em 1820, a reformista da saúde, a inglesa Florence Nightingale ${ }^{(9)}$.

Na América Latina essa ciência começa a sua vinculação com a universidade a partir dos anos 30, sendo que as 
licenciaturas se desenvolvem a partir dos anos 60 e os programas de pós-graduação com especializações e mestrados a parir dos anos 80, primeiramente no Brasil, e atualmente encontram-se em expansão para os demais países ${ }^{(10)}$.

A formação da enfermagem moderna no Mercosul foi fortemente influenciada pelas relações sociais, políticas, de educação e de saúde, que procuraram atender as necessidades específicas de cada um dos países, tanto da comunidade quanto do setor saúde.

A partir da década de 90, vários encontros promovidos por diferentes entidades foram realizados para debater as questões relativas à mobilidade profissional no Mercosul, culminando na formação do Conselho Regional de enfermagem do Mercosul, com o bjetivo de ser o fórum de discussão dos problemas e de encaminhamentos de propostas da enfermagem na região $^{(7)}$.De modo geral, naquela época e ainda hoje percebe-se a insuficiência de enfermeiros nos países do Mercosul, analisada por meio do indicador do número de enfermeiros por habitantes; a intensa desigualdade de distribuição geográfica com concentração de profissionais em áreas urbanas e mais desenvolvidas; a predominância de auxiliares na assistência direta com o paciente; precárias condições de trabalho; emigração destes profissionais para países em desenvolvimento decorrente dos baixos salários e alto risco laboral, que desse modo desestimula também a procura da graduação ${ }^{(7)}$

A trajetória da consolidação dos cursos de graduação em enfermagem no Brasil evidencia assimetrias entre as diferentes regiões, observando-se, especialmente, a grande concentração nos pólos econômicos sendo este um desafio a ser enfrentado pela categoria. A realidade brasileira permite refletir acerca dos desequilíbrios regionais e sobre a necessidade da formulação de estratégias específicas visando a criação de parâmetros norteadores para a expansão do sistema de formação dos profissionais enfermeiros ${ }^{(11)}$.

No Cone Sul permanece, ainda, a predominância do trabalho hospitalar, com destaque da ação de enfermagem na administração dos serviços de enfermagem e em unidades ou serviços de alta complexidade e tecnologia mais avançada, com prejuízo na assistência à saude coletiva e na atenção básica $^{(7)}$.

Assim, o grande desafio na formação do enfermeiro é transpor o domínio teórico-prático exigido pelo mercado de trabalho, e investir no desenvolvimento de agentes inovadores e transformadores da realidade, inseridos e valorizados no mundo do trabalho. Sendo as principais tendências de transformações educacionais: a aprendizagem baseada em problemas e evidências; a aprendizagem direcionada para a aquisição de competências cognitivas e tecnológicas em prevalência à apreensão de aptidões específicas; o trabalho na transdisciplinariedade; a incorporação da avaliação econômica e da bioética nos currículos e o estímulo à investigação(12)

Portanto, a articulação educacional entre os países do Mercosul e os Projetos Políticos Pedagógicos do ensino universitário são formas potenciais para o avanço da integração regional, para a qualificação das profissões, da cidadania regional, e da democracia. Este processo de articulação educacional deve ser observado como um espaço coletivo para a construção de acordos e compromissos a fim de influenciar a elaboração, implementação e gestão de políticas educacionais comuns, ressaltando a educação como eixo fundamental no cenário dos processos de integração entre regiões e países.

\section{CONSIDERAÇÕES FINAIS}

Para o desenvolvimento de uma profissão é necessário desenvolver profissionais críticos, reflexivos e com compromisso político, tornando-se fundamental investir na formação e na qualidade dos centros de ensino em Enfermagem. Todavia, são necessários muitos esforços no sentido de direcionar a construção do conhecimento, com respeito às diversidades humanas e culturais, e para tal o Setor Educativo do Mercosul tem realizado ações promissoras nesse sentido.

O setor da gestão do trabalho e da educação em saúde apresenta, na maior parte dos países da América Latina, problemas de natureza semelhante, como o número reduzido de profissionais na assistência e a pouca valorização da profissão e do profissional. Assim, investir em um sistema que certifique a qualidade dos cursos de graduação, respeitando as diferenças culturais, o ensino, a pesquisa e extensão são passos primordiais para potencializar o desenvolvimento da Enfermagem no Mercosul.

Logo, manter-se atualizado, divulgar e participar do Sistema de Acreditação para as escolas de Enfermagem, em um processo que fomente a valorização profissional, a integração acadêmica e política e a qualidade do ensino da formação, poderá permitir a validação de diplomas e um futuro de livre movimentação de profissionais humanos, globalizados e qualificados entre os países do Mercosul.

\section{REFERÊNCIAS}

1. Mercosur Educativo. Sistema ARCU-SUR: Sistema de Acreditación de Carreras Universitarias para reconocimiento regional de la calidad académica de sus respectivas titulaciones en el MERCOSUR y estados Asociados. Manual de Procedimento [monografia na internet]. Rede de Agencias Nacionales de Acreditación; 2008. [acesso em 8 ago 2009]. Disponível em: <www. sicmercosul.mec.gov.br $>$

2. Raizer L, Fachineto RF, Neves CEB. Educação para a integração: rumo ao mercosul educacional? Núcleo Disciplinar: Educação para a Integração [monografia na internet]. [acesso em 4 set 009]. Disponível em: < http://www.cori. unicamp.br/jornadas/completos/UFRGS/Leandro\%20Raizer.doc $>$ 
3. Soares CMPCB. Integração educacional: Educação Superior e Legislação do Mercosul. In: Anais do Seminário de Direito Internacional [evento na internet]. 2009 ago 11; Rio de Janeiro, Brasil [acesso em 4 set 2009]. Disponível em: < www.ceinter.com.br/.../14-INTEGRAcAO-EDUCACIONAL-Educacao-Superior-e-Legislacao-do-Mercosul-. $\mathrm{htm}>$

4. Ministério das Relações Exteriores. Mercosul [monografia na internet]. [acesso em 8 set 2009]. Disponível em: < http://www.mercosul.gov.br>

5. Raizer L. Educação paraa integração: Rumoao mercosul educacional? Políticas Educativas [monografia na internet]. 2007 [acesso em 1 set 2009]. Disponível em: <http://www.sic. inep.gov.br/index.php?option $=$ com_docman\&task $=$ cat view\&gid $=125 \&$ ltemid $=49$ \&lang $=\overline{b r}>$

6. Instituto Nacional de Estudos e Pesquisas Educacionais Anísio Teixeira. Estudo Analítico Comparativo do Sistema Educacional do Mercosul (2001-2005) [monografia na internet]; 2008. [acesso em 27 set 2009]. Disponível em: < http://www.publicacoes.inep.gov.br/arquivos>

7. Vieira ALS, Filho AA, Garcia ACP, Donato M. Os Enfermeiros no Mercosul: Recursos Humanos, Regulação e
Formação Profissional Comparada. [monografia na internet]. Rio de Janeiro: Fundação Oswaldo Cruz; 2006. [acesso em 8 set 2009]. Disponível em: <http://portal. saude.gov.br/portal/saude/profissional/visualizar_texto. cfm?idtxt $=27170>$

8. Ministério da Educação. Mercosul Educacional [monografia na internet]. [acesso em 08 ago 2009]. Disponível em: $<$ www.sicmercosul.mec.gov.br $>$

9. Conselho Regional de Enfermagem/Rio de Janeiro. História da Enfermagem no Brasil [monografia na internet]. 2005 [acesso em 15 out 2009]. Disponível em: <http:// www.medicinaintensiva.com.br/enfermagem-historia. htm >

10. Malvárez SM, Castrillón-Agudelo MC. Panorama de la fuerza de trabajo en enfermería en América Latina: Segunda parte. Rev Enferm IMSS 2006;14(3):145-65.

11. Teixeira E, Vale EC, Fernandes JD, De Sordi MRL. Trajetória e tendências dos cursos de enfermagem no Brasil. Rev Bras Enferm 2006;59(4):479-87.

12. Ito EE, Peres AM, Takahashi RT, Leite MMJ. O ensino de enfermagem e as diretrizes curriculares nacionais: utopia x realidade. Rev Esc Enferm USP 2006;40(4):570-5. 